\title{
Segmental colitis associated with diverticulosis syndrome
}

\author{
Hugh James Freeman
}

Hugh James Freeman, Department of Medicine (Gastroenterology), University of British Columbia, Vancouver V6T 1W5, Canada

Author contributions: Freeman HJ contributed all to this paper. Correspondence to: Dr. Hugh James Freeman, MD, FRCPC, FACP, Department of Medicine (Gastroenterology), University of British Columbia Hospital, 2211 Wesbrook Mall, Vancouver V6T1W5, Canada.hugfree@shaw.ca

Telephone: +1-604-8227216 Fax: +1-604-8227236

Received: July 24, 2008 Revised: September 12, 2008

Accepted: September 19, 2008

Published online: November 14, 2008

\begin{abstract}
An inflammatory process that involves the sigmoid colonic segment associated with diverticular disease (SCAD) appears to be a distinct clinical and pathological disorder. It has been described in older adults, often presenting with rectal bleeding. Most of the patients seem to respond to treatment only with a 5-aminosalicylate, but some spontaneously resolve with no treatment. Endoscopic evaluation usually shows a non-specific inflammatory process localized in the sigmoid colon alone that may resolve completely with histologically normal colonic mucosa. Repeated symptomatic events with discrete episodes of segmental colitis may occur, but most patients have an entirely benign clinical course. Definition of the underlying molecular events that occur with SCAD may be critically important in understanding the critical elements present in a colonic inflammatory process that can completely resolve without pharmacological or biological treatment.
\end{abstract}

(c) 2008 The WJG Press. All rights reserved.

Key words: Segmental colitis; Diverticulosis; Crohn's disease; Natural history; Ulcerative colitis; Colon cancer

Peer reviewer: Francis Seow-Choen, Professor, Seow-Choen Colorectal Centre, Mt Elizabeth Medical Centre, Singapore, 3 Mt Elizabeth Medical Centre \#09-10, 228510, Singapore

Freeman HJ. Segmental colitis associated with diverticulosis syndrome. World J Gastroenterol 2008; 14(42): 6442-6443 Available from: URL: http://www.wjgnet. com/1007-9327/14/6442.asp DOI: http://dx.doi.org/10.3748/ wjg. 14.6442

\section{INTRODUCTION}

Segmental colonic involvement with a well circumscribed inflammatory process may occur in different forms of infectious colitis or inflammatory bowel disease. In infectious disease, multiple different sites within the colon are likely to be involved, sometimes with small bowel changes. In ulcerative colitis, the rectum or rectosigmoid segment is generally involved with disease extending in a continuous pattern proximally within the colon for a variable distance. During colonoscopic examination in ulcerative colitis, this inflammatory process seems to be well demarcated, while in others, less so. In Crohn's disease, any segment of the colon may be involved, most often cecum and/or ascending colon. Concomitant small intestinal disease is also present. In recent years, other less common, but distinct types of inflammatory disease have become better recognized. One segmental form associated with diverticulosis, usually involving only the sigmoid colon, is the so-called "SCAD syndrome", or more precisely, segmental colitis associated with diverticulosis (SCAD) ${ }^{[1-5]}$.

\section{CLINICAL FEATURES OF SCAD}

This form of segmental involvement, especially if only the sigmoid colon is affected, frequently presents with bloody stools. In some, but not all, abdominal pain, cramping discomfort, or diarrhea may occur. Males are generally affected more often than females ${ }^{[6]}$, and usually, most suffer from the initial onset of symptoms after 40 or 50 years of age, somewhat different from the usual female predominant distribution of Crohn's disease, including Crohn's disease of the colon ${ }^{[6]}$. In Crohn's disease, as well, studies have shown that over $80 \%$ of adults are usually diagnosed well before age $40^{[6-8]}$. Like other forms of idiopathic inflammatory bowel diseases, the cause and pathogenesis needs to be better characterized and elucidated ${ }^{[1,5,9]}$. Endoscopic examination reveals a localized sigmoid inflammatory process with normal rectal and proximal colonic mucosa. Detailed biopsy examination of the entire colonic mucosa shows a localized non-specific mucosal inflammatory process only in the sigmoid $\operatorname{colon}^{[6,10]}$.

\section{SELECTION BIAS}

In some, an earlier diagnosis of a resected colonic neoplasm (i.e. adenoma) is not infrequent ${ }^{[6]}$. As a 
result, a form of selection bias may be present as this subgroup of older patients may be simply more aware of the significance of rectal bleeding and their particular increased risk for recurrent adenomas or colon cancer. Therefore, many often seek expedient medical investigation to define their symptoms and alleviate their anxiety. The good news of detection of inflammatory mucosal disease, rather than colonic cancer, is the virtually immediate relief of their concerns.

\section{LONG-TERM NATURAL HISTORY}

Even better news is that most diagnosed with this segmental form of colitis, if followed over several years, remain well, usually resolving completely within a few weeks or months without recurrence ${ }^{[6]}$. Repeat endoscopic studies, including biopsies, reveal no evidence of residual inflammatory change. Some may have been initially treated with oral 5-aminosalicylates or other symptomatic agents. However, it is not certain that these medications are really necessary since some have spontaneously resolved with no traditional pharmacologic measures. Occasionally, other drugs have been used, including steroids, suggesting that there may be a spectrum of disease severity observed over time. In some cases, discrete episodes of recurrent symptoms and endoscopic changes have been defined and resection of the sigmoid colon was very rarely done. To date, no particular predisposition to colonic neoplastic disease, including invasive carcinoma, has been documented.

\section{CLINICAL SIGNIFICANCE}

This entity has special significance. First and most important, this inflammatory process is most often selflimited. Typically, the clinical course of SCAD is benign and it resolves without further recurrence or need for treatment. Due to similarities with other forms of inflammatory bowel disease, particularly Crohn's disease, the implications of an inaccurate diagnosis are evident. A case of segmental colitis involving the sigmoid colon, labeled as Crohn's colitis, might lead the treating physician or clinical trial investigator (in the case of new agents) to conclude that a positive outcome was due to the treatment provided rather than the natural history of an otherwise clinically benign inflammatory process. Anecdotal treatment success, including open label treatment trials of new agents for Crohn's disease, may be quite difficult to evaluate, especially if there are claims of "complete mucosal healing". Second, utilization of modern classification methods used for entities, such as Crohn's disease, that define age of diagnosis, location within the intestinal tract and clinical behavior may lead to further recognition of such entities so as to permit more precise treatment ${ }^{[7,8]}$. Finally, a "new" or distinct colonic inflammatory process that usually spontaneously resolves, such as SCAD, raises a critical need to better understand the molecular events that might be present allowing a long-term benign disease course. More precise treatments for other inflammatory colonic diseases aimed at cure, rather than remission, might then emerge.

\section{REFERENCES}

1 Sladen GE, Filipe MI. Is segmental colitis a complication of diverticular disease? Dis Colon Rectum 1984; 27: 513-514

2 Peppercorn MA. Drug-responsive chronic segmental colitis associated with diverticula: a clinical syndrome in the elderly. Am J Gastroenterol 1992; 87: 609-612

3 Gore S, Shepherd NA, Wilkinson SP. Endoscopic crescentic fold disease of the sigmoid colon: the clinical and histopathological spectrum of a distinctive endoscopic appearance. Int J Colorectal Dis 1992; 7: 76-81

4 Imperiali G, Meucci G, Alvisi C, Fasoli R, Ferrara A, Girelli CM, Rocca F, Saibeni S, Minoli G. Segmental colitis associated with diverticula: a prospective study. Gruppo di Studio per le Malattie Infiammatorie Intestinali (GSMII). Am J Gastroenterol 2000; 95: 1014-1016

5 Goldstein NS, Leon-Armin C, Mani A. Crohn's colitis-like changes in sigmoid diverticulitis specimens is usually an idiosyncratic inflammatory response to the diverticulosis rather than Crohn's colitis. Am J Surg Pathol 2000; 24: 668-675

6 Freeman HJ. Natural history and long-term clinical behavior of segmental colitis associated with diverticulosis (SCAD syndrome). Dig Dis Sci 2008; 53: 2452-2457

7 Freeman HJ. Application of the Montreal classification for Crohn's disease to a single clinician database of 1015 patients. Can J Gastroenterol 2007; 21: 363-366

8 Freeman HJ. Granuloma-positive Crohn's disease. Can J Gastroenterol 2007; 21: 583-587

9 Evans JP, Cooper J, Roediger WE. Diverticular colitis therapeutic and aetiological considerations. Colorectal Dis 2002; 4: 208-212

10 West AB, Losada M. The pathology of diverticulosis coli. J Clin Gastroenterol 2004; 38: S11-S16

S- Editor Xiao LL L- Editor Ma JY E- Editor Yin DH 